\title{
Serum Clusterin in Psoriasis: Relation to Metabolic Syndrome
}

\section{Ahmed Ghazy El-Sayed Ghazy ${ }^{1, *}$ MSc.; Ahmed Sadek Mohamed Salem ${ }^{2}$ MD.; Ahmad Kamel Seddeik Abdel- hameed $^{2}$ MD.; Ahmed Mohamed Abdul-Rahman Tahoun ${ }^{3}$ MD.}

\author{
* Corresponding Author: \\ Ahmed Ghazy El-Sayed Ghazy \\ dr.ghazy20@gmail.com
}

Received for publication May 24, 2020; Accepted September 16, 2020; Published online September 16, 2020.

\section{Copyright 2020 The Authors published by Al-Azhar University, Faculty of Medicine, Cairo, Egypt. All rights reserved. This an open-access article distributed under the legal terms, where it is permissible to download and share the work provided it is properly cited. The work cannot be changed in any way or used commercially.}

doi: 10.21608/aimj.2020.30442.1232

${ }^{I}$ Dermatology, Venereology and Andrology Department, Kobri AlKobba Military Medical Complex, Cairo, Egypt.

${ }^{2}$ Dermatology, Venereology and Andrology Department, Al-Azhar University, Cairo, Egypt.

${ }^{3}$ Clinical Pathology Department, AlAzhar University, Cairo, Egypt.

\begin{abstract}
Background: Psoriasis is a common long standing immune-related disease that affects $1 \%-3 \%$ of the general people and is characterized by inflammation and hyperproliferation of epidermal cells. However, Psoriasis has been known to be a systemic disorder related to metabolic syndrome including obesity, insulin resistance, hypertension and atherogenic dyslipidemia. There are higher morbidity and mortality rates in psoriatic patients with atherosclerosis and cardiovascular diseases. Clusterin "apolipoprotein J" plays an important role in metabolic disorders linked with inflammation and oxidative stress such as diabetes, obesity, atherosclerosis and insulin resistance.

Aim of work: To compare clusterin levels between psoriatic patients and controls, between patients who have and have no metabolic syndrome and to confine the role of clusterin in disease severity.

Patient and Methods: This study was done on 30 psoriatic patients who have metabolic syndrome (group A), 30 psoriatic patients without metabolic syndrome (group B) and 30 sex- and age-matched healthy volunteers as controls (group C). Written consent was signed by each participant before initiation of the study. All patients undergone full history taking, general examination and PASI scoring for psoriasis severity. Serum samples from all participants undergone routine investigations and clusterin levels were determined by ELISA.

Results: serum clusterin levels showed no difference between patients and controls also there was no difference in clusterin levels among patients with and without metabolic syndrome.

Conclusion: Based on our results clusterin has no role in psoriasis pathogenesis or in psoriasis comorbidities, clusterin has no role in disease severity and we cannot ensure its role in the mechanism of $\mathrm{CV}$ risks with psoriasis.

Keywords: Psoriasis; Clusterin; Psoriasis Area Severity Index; Metabolic Syndrome; Keratinocytes.
\end{abstract}

Disclosure: The authors have no financial interest to declare in relation to the content of this article. The Article Processing Charge was paid for by the authors.

Authorship: All authors have a substantial contribution to the article.

\section{INTRODUCTION}

Psoriasis is a common long standing immune-related disease that affects $1 \%-3 \%$ of the general people and is characterized by inflammation and hyperproliferation of epidermal cells. ${ }^{1,2}$ However, it has been known to be a systemic disorder related to metabolic syndrome including obesity, insulin resistance, hypertension and atherogenic dyslipidemia. ${ }^{3}$ The intensity of inflammation and skin changes in psoriasis may not only indicate the severity of psoriasis but also that of other systemic pathologies. $^{4}$

Psoriasis patients had higher rates of insulin resistance, hypertension, dyslipidemia, and obesity which are risk factors for further cardio-vascular problems. ${ }^{1}$ There are higher morbidity and mortality rates in psoriatic patients with atherosclerosis and cardiovascular diseases. ${ }^{4}$ previous studies found that there was no increased mortality rate for outpatient psoriatic patients, but there was an increased mortality rate from cardiovascular diseases among hospitalized psoriatic patients. ${ }^{5,6}$

Clusterin "apolipoprotein $\mathrm{J}$ " is a disulfide glycoprotein with its code at chromosome 8 which called the CLU gene. It shares in the antiapoptotic process, so plays a role in neurodegenerative disorders, inflammation and tumors. ${ }^{7}$ CLU plays an important role in metabolic disorders linked with inflammation and oxidative stress such as diabetes, obesity, atherosclerosis and insulin resistance. ${ }^{8,9}$ 
Clusterin is a protein element of high-density lipoproteins. It had a protective role in myocarditis and athero-sclerosis. It could be considered as an inhibitor of future coronary events ${ }^{16}$. But recently Zhu et el. found that clusterin increased in patients with early coronary artery diseases. ${ }^{15}$

Buquicchio et al. found that clusterin is elevated in psoriatic patients having comorbidites like metabolic syndrome and cardiovascular diseases, and suggested further studies to strengthen the value of serum levels of clusterin / apo $\mathbf{J}$ and to suggest its use as a new marker in psoriasis. ${ }^{10}$ Garcia- Rodriguez et al. observed that plasma clusterin was reduced in psoriasis patients compared with healthy controls but the study had a small sample size. ${ }^{14}$ while, Ataseven et al. reported that there was no difference in clusterin levels among psoriatic patients and controls. $^{12}$

The aim of this work to define the level of clusterin among psoriatic patients in comparison to normal controls, to compare clusterin levels in psoriatic patients having and not having metabolic syndrome and to define the role of clusterin levels in disease severity.

\section{PATIENT AND MATERIALS}

This study is a case-control study. It was done on 60 psoriatic patients and 30 sex- and age-matched healthy people. They were enrolled from Dermatology Outpatient Clinic at El-Hussein University Hospital and Kobry Al-Kobba Military Hospital in the period from $1 / 1 / 2019$ to $15 / 9 / 2019$.

All psoriasis patients have severe psoriasis vulgaris with PASI > 10. On the other hand, patients with other types of psoriasis (other than vulgaris), mild psoriasis (PASI < 10) and known cardiac patients were excluded.

Patients with metabolic syndrome had at least 3 of the following: Serum triglycerides $150 \mathrm{mg} / \mathrm{dl}$ or above, abdominal obesity with a waist circumference of $102 \mathrm{~cm}$ or more in males and $88 \mathrm{~cm}$ or more in females, HDL cholesterol $40 \mathrm{mg} / \mathrm{dl}$ or lower in males and $50 \mathrm{mg} / \mathrm{dl}$ or lower in females, Fasting blood glucose of $100 \mathrm{mg} / \mathrm{dl}$ or above and Blood pressure of $130 / 85$ or more.

All subjects signed consent to participate in this work after an explanation of the steps of the study. The study was accepted by research ethical committee at Al-Azhar University and fulfilled all the ethical aspects required in human research.

The study had 30 patients had psoriasis only (group B) and 30 patients had psoriasis and metabolic syndrome (group A) and 30 sex and age-matched healthy people (group C).
All patients undergone full History taking [personal history, present illness, family history, other dermatological or systemic diseases, and previous therapy]. written consent was signed by each participant before initiation of the study.

In addition, all patients were subjected to general examination and PASI scoring which estimates the disease severity in relation to three parameters including redness [R], thickness [infiltration] [T] and scaling [desquamation] [S]. ${ }^{11}$

Venous blood sample $(3 \mathrm{ml})$ was collected from psoriatic patients and controls and left to clot for 20 minutes at ordinary temperature. The sample was centrifuged at a speed of 2000 - 3000 r.p.m for 20 minutes, and serum was taken and left at $-20^{\circ} \mathrm{C}$ till assayed.

Routine investigations were done as CBC, FBS, 2 hpp blood sugar, total cholesterol, triglyceride, LDL and HDL.

Serum clusterin was determined by a commercially available ELISA kit manufactured at Shanghai Korain Biotech Company, Shanghai, China; kit's no is $\mathrm{E} 1189 \mathrm{Hu}$ with package size of $96 \mathrm{~T}$ per box and assay range 1-300ng/ml. This kit uses enzyme-linked immune sorbent assay (ELISA) depending on the Biotin double antibody sandwich technology for assayment of the Human Clusterin (CLU). Add the sample to the wells, which are pre-covered with Clusterin (CLU) monoclonal antibody and incubate. Later on, combine anti CLU antibodies asorted with biotin to gather with streptavidin-HRP forming an immune complex. Remove ungathered enzymes after washing. Combine substrate $\mathrm{A}$ and $\mathrm{B}$. Then the solution will turn blue and change into yellow affected by acid. The shades of the solution and the concentration of Human Clusterin (CLU) are correlated positively.

Statistics: Descriptive statistics were calculated for the data in the form of Mean and standard deviation (SD) for quantitative data and Frequency and distribution for qualitative data. In the statistical comparison between different groups, the significance of difference was tested using one of the following tests: Student's $t$-test, ANOVA test (F value), chi-square test $\left(X^{2}\right.$-value), fisher exact test (FET) or Correlation coefficient. A $P$-value $<0.05$ was considered significant $(*)$ while $>0.05$ insignificant $\mathrm{P}$-value $<0.01$ was considered highly significant $(* *)$

\section{RESULTS}

The present study was conducted on 60 psoriasis patients and 30 persons as controls. Their mean age was 34.28 years, they were 80 males [ $88.9 \%$ ] and 10 females [11.1\%], mean height was 167.01 , mean 
weight 75.94, mean BMI 27.46 and mean waist circumference 92.48. (Table 1)

The 60 patients were divided into 30 psoriasis patients with metabolic syndrome group (A) with mean PASI 12.336, mean duration 6.97, mean clusterin level 89.55 and most of them had gradual onset $90 \%$ and 30 psoriatic patients without metabolic syndrome group (B) with mean PASI 12.836, mean duration 5.75, mean clusterin level 105.88 and most of them had gradual onset $80 \%$. The controls had mean clusterin level of 95.53. (Table 2)

No significant differences were found in serum clusterin level according to other studied parameters in all studied cases. (Table 3)

\begin{tabular}{|l|l|l|l|}
\hline \multirow{2}{*}{ Age } & \multicolumn{3}{|c|}{ The studied groups (90) } \\
\cline { 2 - 4 } & Mean & \pm SD & Range \\
\hline Sex n (\%) & 34.28 & 16.14 & $3.0-75.0$ \\
Male & & & \\
Female & 80 & 88.9 & \\
\hline Ht & 10 & 11.1 & \\
\hline Wt & 167.01 & 18.99 & $70.0-182.0$ \\
\hline BMI & 75.94 & 17.57 & $14.0-98.0$ \\
\hline WC & 27.46 & 4.13 & $15.0-39.0$ \\
\hline
\end{tabular}

Table 1: Distribution of the studied groups according to personal data.

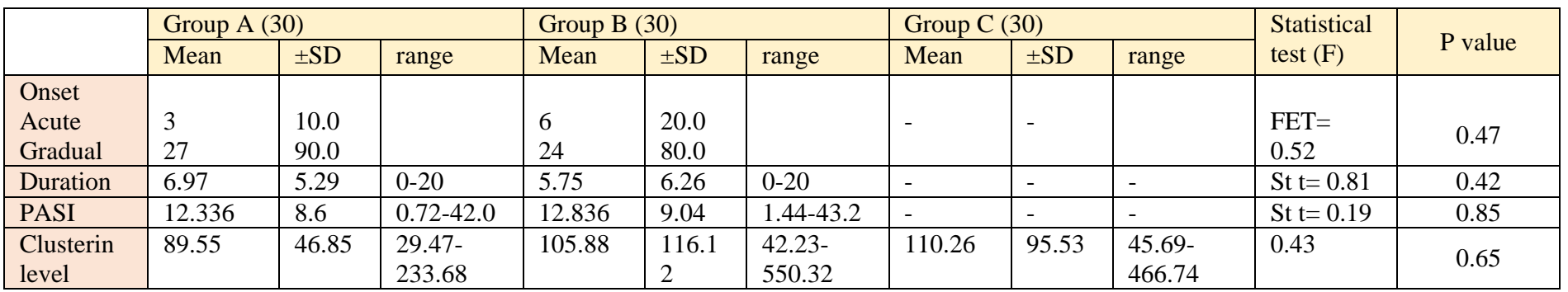

Table 2: Comparison between the studied groups according to clinical data and clusterin levels.

\begin{tabular}{|c|c|c|c|c|c|c|}
\hline & \multicolumn{2}{|l|}{ Group (A) } & \multicolumn{2}{|l|}{ Group (B) } & \multicolumn{2}{|l|}{ Group (C) } \\
\hline & $\begin{array}{l}\text { Statistical } \\
\text { test (r) }\end{array}$ & $\mathrm{P}$ value & $\begin{array}{l}\text { Statistical } \\
\text { test }(r)\end{array}$ & $\begin{array}{l}\mathrm{P} \\
\text { value }\end{array}$ & $\begin{array}{l}\text { Statistical } \\
\text { test }(r)\end{array}$ & $\begin{array}{l}\mathrm{P} \\
\text { value }\end{array}$ \\
\hline Age & 0.309 & $\begin{array}{l}0 . \\
097\end{array}$ & 0.15 & 0.42 & 0.485 & 0.007 \\
\hline $\mathrm{Ht}$ & 0.059 & 0.76 & -0.26 & 0.16 & 0.167 & 0.379 \\
\hline $\mathrm{Wt}$ & 0.30 & 0.11 & -0.21 & 0.28 & 0.243 & 0.195 \\
\hline BMI & -0.03 & 0.86 & 0.006 & 0.98 & 0.152 & 0.422 \\
\hline WC & 0.24 & 0.198 & 0.014 & 0.94 & 0.338 & 0.073 \\
\hline FBS & -0.11 & 0.58 & -0.37 & 0.046 & 0.011 & 0.956 \\
\hline $2 \mathrm{H} \mathrm{PP}$ & -0.15 & 0.44 & -0.29 & 0.12 & 0.194 & 0.304 \\
\hline $\begin{array}{l}\text { Total } \\
\text { cholesterol }\end{array}$ & -0.26 & 0.16 & -0.14 & 0.47 & 0.264 & 0.158 \\
\hline TG & -0.095 & 0.62 & -0.26 & 0.16 & 0.106 & 0.576 \\
\hline LDL & -0.35 & 0.06 & -0.15 & 0.42 & 0.269 & 0.15 \\
\hline HDL & 0.20 & 0.29 & -0.06 & 0.74 & -0.39 & 0.031 \\
\hline Duration & 0.21 & 0.26 & 0.314 & 0.09 & & \\
\hline PASI & 0.22 & 0.24 & -0.028 & 0.88 & & \\
\hline
\end{tabular}

Table 3: Correlation of Clusterin level with other studied parameters in patients and controls. 


\begin{tabular}{|l|l|l|l|l|l|l|l|c|}
\hline & \multicolumn{3}{|c|}{ Group A+ B (60) } & \multicolumn{3}{c|}{ Group C (30) } & Statistical & \multirow{2}{*}{ P value } \\
\cline { 2 - 7 } & Mean $($ st t) & Mean & \pm SD & Range & Range & 0.54 \\
\hline Clusterin level & 97.72 & 88.17 & $29.47-550.32$ & 110.26 & 95.53 & $45.69-466.74$ & 0.62 & 0.62 \\
\hline
\end{tabular}

Table 4: Comparison of Clusterin concentration between all psoriasis patients and controls.

\begin{tabular}{|l|l|l|l|l|l|l|l|c|}
\hline & \multicolumn{3}{|c|}{ Group A (30) } & \multicolumn{3}{c|}{ Group C (30) } & \multirow{2}{*}{$\begin{array}{c}\text { Statistical } \\
\text { test (st t) }\end{array}$} & \multirow{2}{*}{ P value } \\
\cline { 2 - 8 } & Mean & \pm SD & Range & Mean & \pm SD & Range & 1.07 & 0.29 \\
\hline Clusterin level & 89.55 & 46.85 & $29.47-233.68$ & 110.26 & 95.53 & $45.69-466.74$ & 1.29 \\
\hline
\end{tabular}

Table 5: comparison of clusterin concentration between patients having metabolic syndrome and controls.

\begin{tabular}{|l|l|l|l|l|l|l|c|c|}
\hline & \multicolumn{3}{|c|}{ Group B (30) } & \multicolumn{3}{c|}{ Group C (30) } & \multirow{2}{*}{$\begin{array}{c}\text { Statistical } \\
\text { test (st t) }\end{array}$} & \multirow{2}{*}{ P value } \\
\cline { 2 - 9 } & Mean & \pm SD & Range & Mean & \pm SD & Range & 45.159 & 0.874 \\
\hline Clusterin level & 105.88 & 116.12 & $42.23-550.32$ & 110.26 & 95.53 & $45.69-466.74$ & 0.159 \\
\hline
\end{tabular}

Table 6: comparison of clusterin concentration between patients without metabolic syndrome and controls.

\begin{tabular}{|l|l|l|l|l|l|l|l|c|}
\hline & \multicolumn{3}{|c|}{ Group A (30) } & \multicolumn{3}{c|}{ Group B (30) } & \multirow{2}{*}{$\begin{array}{c}\text { Statistical } \\
\text { test (st t) }\end{array}$} & \multirow{2}{*}{ P value } \\
\cline { 2 - 8 } & Mean & \pm SD & Range & Mean & \pm SD & Range & 0.71 & 0.48 \\
\hline Clusterin level & 89.55 & 46.85 & $29.47-233.68$ & 105.88 & 116.12 & $42.23-550.32$ & 0.71 \\
\hline
\end{tabular}

Table 7: comparison of clusterin concentration between patients having and not having metabolic syndrome.

\section{DISCUSSION}

In our study comparison between clusterin serum levels between psoriatic patients and controls revealed no difference. This was matched with the result reported by Ataseven et al. that reported that there was no difference in clusterin serum levels between psoriatic patients and controls. ${ }^{12}$

Hashem et al. supported Buquicchio et al. conclusions and reported higher levels of serum clusterin in psoriatic patients than controls and found that Clusterin levels had a significant positive relation with PASI score. With no significant correlation in clusterin level with other studied parameters in all psoriasis cases. ${ }^{10,13}$

The results obtained by Garcia- Rodriguez et al. observed that plasma clusterin was reduced in psoriasis patients compared with healthy controls but the study had a small sample size. ${ }^{14}$

In this study there was a comparison between psoriatic patients with metabolic syndrome and controls where there were differences in correlation to any other parameter. This comparison revealed no difference in serum clusterin levels. These results match with Ataseven et al. that reported that there was no difference in clusterin levels among psoriatic patients and controls. This is not consistent with Hashem et al. that suggest that serum clusterin levels were higher than controls and suggest the presence of psoriasis- metabolic syndrome pathogenic interactions and with Zhu et al. who concluded that serum values of clusterin were increased in the premature form of coronary artery disease. ${ }^{12,13,15}$

Comparing between psoriatic patients having metabolic syndrome and psoriatic patients having no metabolic syndrome revealed no significant difference in clusterin serum levels. This matches with Garcia- Rodriguez et al. who however said that clusterin levels are decreased in psoriatic patients than controls, but also found that there was no difference in its levels in patients haning and having no metabolic syndrome. ${ }^{14}$

According to our study, there was no relation between clusterin serum levels and PASI score in psoriatic patients having and having no metabolic syndrome which mean that clusterin has no role in disease severity and can't play a role in eliminating the disease. These results don't match with Hashem et al. who suggested that clusterin level showed a significant correlation with PASI score and it could be a useful marker for severity of the disease. ${ }^{13}$

Kyrylowicz et al refered elevated levels of clusterin to its defensive role against the inflammation associated with psoriasis. ${ }^{17}$ on another hand, increased rate of cardio vascular diseases in psoriasis is associated with elevated levels of proinflammatory cytokines like tumor necrosis factor- alpha, interleukin 1, and cardiotropin-1. ${ }^{18}$ Recently, Zhu et al. found elevated clusterin levels in premature form of coronary artery disease; so suggested that it may play a protective role and used as a diagnostic criteria for premature CAD. ${ }^{15}$

We may owe this difference between the results of our study and other studies to the fact that clusterin remains an enigmatic protein and although its various biological functions it needs further studies to understand the certain role plays in psoriasis and this may explain the difference between these various studies. ${ }^{19}$ 


\section{CONCLUSION}

Based on our results; clusterin had no role in psoriasis pathogenesis, comorbidities and not affected by PASI score so cannot be used as a biomarker for disease severity. Also, we couldn't ensure the role of clusterin in pathogenesis of $\mathrm{CV}$ risks in psoriatic patients.

\section{REFERENCES}

1. Menter A, Gottlieb A, Feltman SR, et al. Guidelines of care for the management of psoriasis and psoriatic arthritis. $J \quad A m$ AcadDermatol. 2008; 58(5): 826-50.

2. Boehncke WH and Schon MP. "Psoriasis". Lancet. 2015; 386:983-94.

3. Gerkowicz A, Pietrzak A, Szepietowski JC, et al Biochemicl markers of psoriasis as a metabolic disease. Folia Histochem Cytobiol. 2012; 50:15570.

4. Pietrzak A, Bartosinska J, Chodorowska G, et al. Cardiovascular aspects of psoriasis: An update review. Int J Dermatol. 2013; 52:153-62.

5. Mallbris L, Akre O and Granath F. Increased risk of cardiovascular mortality in psoriasis inpatients but not in outpatients. Eur J Epidemiol. 2004; 19:230-55.

6. Gelfand M, Neimann A, Shin B, et al. Risk of myocardial infraction in patients with psoriasis. JAMA. 2006; 296(14):1735-41.

7. Jones SE, Jomary C. Clusterin. The International Journal of Biochemistery\& Cell Biology. 2002; 34(5): 427-56.

8. Miyata M, Biro S, Kaieda $\mathrm{H}$, et al. Apolipoprotein $\mathrm{J} /$ clusterin is induced in vascular smooth muscle cells after vascular injury. Circulation. Volume 104, Issue 12, 2001, Pages 1407-12.

https://doi.org/10.1161/hc3701.095583
9. Kolati T. Clusterin a key player in cancer chemoresistance and its inhibition. Onco Targets Ther. 2014; 7: 447-56.

10. Buquicchio R. Clusterin: how does it affect psoriatic patients?.JBiolRegulHomeost Agents. 2017; 31(3): 785-9.

11. Langley RG and Ellis CN. Evaluating psoriasis with psoriasis Are and severity index, psoriasis Global Assessment and Lattice System Physicians Global Assessment. J Am Acad Dermatol. 2004; 51:563-9.

12. Ataseven A, Kesli R, Kurtipek GS, et al. Assessment of lipocalin 2, clusterin, soluble tumor necrosis factor receptor-1, interleukin-6, homocysteine, and uric acid levels in patients with psoriasis. Dis Markers. 2014; 2014:541709 .

13. Hashem O, Obaid $\mathrm{Z}$, Abdel same $\mathrm{H}$, et al. Clusterin and Psoriasis; What is The Relation? International journal of medical arts. 2019; 1: 152-6.

14. Garcia-Rodriguez S, Arias-antiago S, PerandresLopez R, et al. Decreased plasma levels of clusterin in patients with psoriasis. Actas Dermosifiliogr. 2013; 104(6): 497-503.

15. Zhu HI, Liu MI, Pan HI, et al. High serum clusterin levels are associated with premature coronary artery diseases in a Chinese population. Diabetes Metab Res Rev. 2019: 1305-18.

16. Negre-Salvayre A, Dousset N, Ferretti G, et al. Antioxidant and cytoprotective properties of high-density lipoproteins in vascular cells. Free Radic Biol Med. 2006; 41: 1031-40.

17. Kuryłowicz A and Nauman J. The role of nuclear factor kappa B in the development of autoimmune diseases: a link between genes and environment. Acta Biochim Pol 2008; 55:629-47.

18. Aronis $\mathrm{KN}, \mathrm{Kim} \mathrm{YB}$ and Mantzoros CS. Clusterin [apolipoprotein J]: wither link with diabetes and cardiometabolic risk. Metabolism 2011; 60:747-8.

19. Bettuzzi S. Chapter 1: Introduction. Advances in cancer research. 2009; 104: 1-8. 